\title{
STUDY OF UNSTEADY AIRFLOW IN MUFFLER AND AIR BOX EQUIVALENT GEOMETRIES
}

\author{
Nicolas-Ivan HATAT * \\ François LORMIER
}

\author{
Le Moteur Moderne - membre du groupe AVL \\ Palaiseau, France
}

\author{
David CHALET \\ Pascal CHESSE \\ LUNAM Université, Ecole Centrale de Nantes, \\ LHEEA - UMR CNRS 6598 \\ Nantes, France
}

\section{ABSTRACT}

The Internal Combustion Engines (ICE) are inherently sources of the flow's unsteadiness in the intake and exhaust ducts. Unsteady flow has a direct impact on the engine's behavior and performance by influencing the filling and emptying of the cylinder. Air intake boxes as well as muffler geometries, which are very commonly used on the twowheeled vehicles, have an impact on pressure levels and so, on air filling and performances levels. Thus, the purpose of this paper is to identify and analyze different typical geometries of these elements (air box and muffler) by comparing the test bench results with those obtained by 3D and $1 \mathrm{D}$ calculations. In this way, it is possible to establish a methodology for modeling the air box and muffler based on experimental tests and the development of 3D and then 1D model.

In a beginning, studies consist in describing the geometry of the air box and muffler using a combination of tubes and simple volumes. During one-dimensional simulations, the gases properties in a volume must be calculated taking into account a method of filling and emptying. Under transient conditions, the pipe element is considered essentially as one-dimensional. The gas dynamic is described by a system of equations: the equations of continuity, momentum and energy. In the three-dimensional case, all tubes and volumes are meshed and solved using various physical models, equations and hypotheses that will be detailed subsequently.

The study is performed on a shock tube bench. One of the main points is that this type of experimental test allows to test easily different pressure ratios, different geometries and to measure direct and inverse flow. In this way, the propagation of a shock wave is studied in our different geometries and is compared to the pressure signals obtained with $1 \mathrm{D}$ and $3 \mathrm{D}$ simulations. Once the 1D modeling is obtained, it must be validated in order to be applied in a simulation for Internal Combustion Engine. Validation will be done by direct comparison of results at each stage to ensure that the models and assumptions used in the calculations are correct.

\section{INTRODUCTION}

For several years, many studies related to the dynamics of gas in the intake and exhaust systems have succeeded [1,2], working first on the reduction of the exhaust noise $[3,4]$ and the characterization of these geometries $[5,6]$. The aim being to know the impact of unsteady flow in some very specific areas of the engine air loops as well as to identify the impact of these phenomena on the Internal Combustion Engine's design and performance. Thus, the computer simulation is often used, especially by the use of one-dimensional software such as BOOST, GT-Power [7] or WAVE.

Inherently, these softwares cannot describe threedimensional phenomena that can occur in an engine. An alternative is to use CFD simulations to complement, either by coupling them to the one-dimensional (co-simulation) or by performing studies using the CFD to characterize this flow element to study and eventually be able to transcribe the results in such a way that the $1 \mathrm{D}$ simulation can incorporate some effects of multidimensional phenomena $[8,9]$. In spite of the phenomena being multidimensional, the flow can be considered as essentially one-dimensional [1]. The geometry, the thermodynamic state of the fluid and the different variables

\footnotetext{
*: PhD Student attached to LUNAM University, working under contract in the company Le Moteur Moderne
} 
characterizing the flow will significantly change only along the longitudinal axis. For these reasons, 1D simulation do the hypothesis of a one-dimensional flow based on the three equations of gas dynamics; the ideal gas equation being commonly used as a closure equation in flow studies into ICE tubes. In order to model correctly, it is also necessary to know the boundary conditions and to describe the influence of duct geometry on the flow.

In this paper, a methodology is established to confront real and CFD tests with one-dimensional simulations. It will also be an opportunity to compare different types of geometries between them. In the first part, the main features of this study consist in describing the geometries used and the assumptions supported. In the second part, the different experimental steps performed as well as installations and software used in this work will be developed. A test bench shock tube is used as a working basis for the acquisition of data and for comparisons between real tests, 1D and 3D simulations. The results of the comparison between measured and calculated data are shown in the third section. Finally, some conclusions are pointed out.

\section{STUDY DESCRIPTION}

The intake and exhaust systems are significant components of an ICE. They are used to supply air to the engine and to discharge the burnt gas. However, this seemingly simple role hides complex phenomena to implement in computer simulations. The elements that constitute the intake and exhaust systems have characteristics conferring properties with various effects: noise reduction (cases of the exhaust muffler), the influence of pressure levels, etc... In our case, this refers to some kinds of geometries that can be found at intake (air box, figure 1) as the exhaust (muffler, figure 2). In fact, they both have quite similar geometries, composed of volumes connected to other ICE components through tubes.
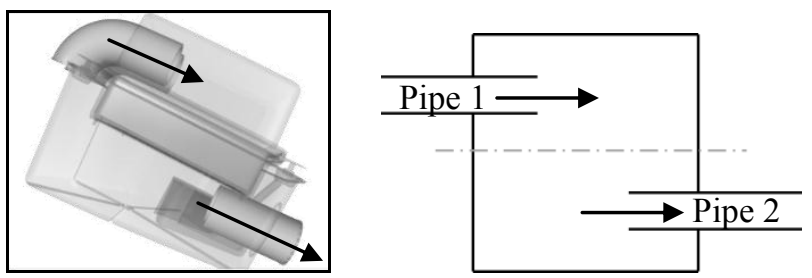

Figure 1. CFD air box and its geometry simplification

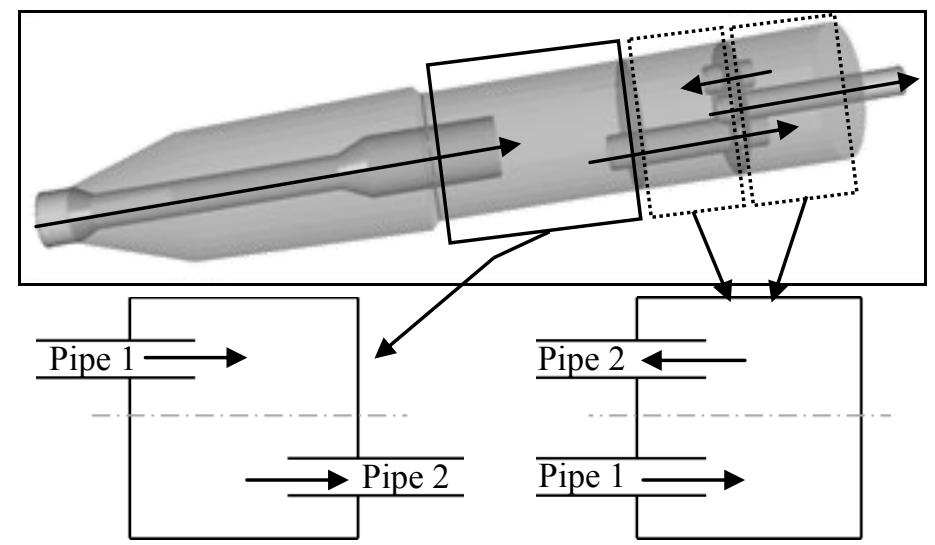

Figure 2. CFD muffler and its geometries simplifications
Keeping in mind the idea to check a 1D simulation correctly reproduces the reality on the flow in an air box and muffler, it was decided to study all geometries that flow is susceptible to meet by comparing actual tests, simulations CFD and 1D; starting with a simple tube and making the system to look more and more complex. Namely, starting from a simple tube, then add a calibrated volume (cylindrical, diameter 95 $\mathrm{mm}$, length $80 \mathrm{~mm}$ ) and another tube, the whole system being coaxial and without penetration of the tubes in the volume as shown in the following figure.

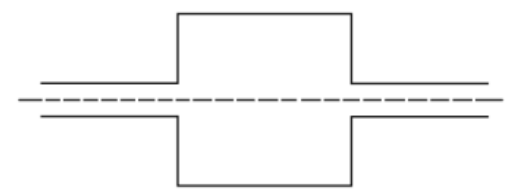

Figure 3. Diagrams of coaxial tubes and volume

Then various configurations derived of it (figure 4). The tubes are shifted relative to the axis of the volume (selected as the reference axis system of the study).

In the following figures, $\mathrm{a}$ and $\mathrm{b}$ are the variables relating to centre distance. $\mathrm{L}_{1}$ and $\mathrm{L}_{2}$ will refer to the length of pipe '1', ' 2 ' in the volume respectively.
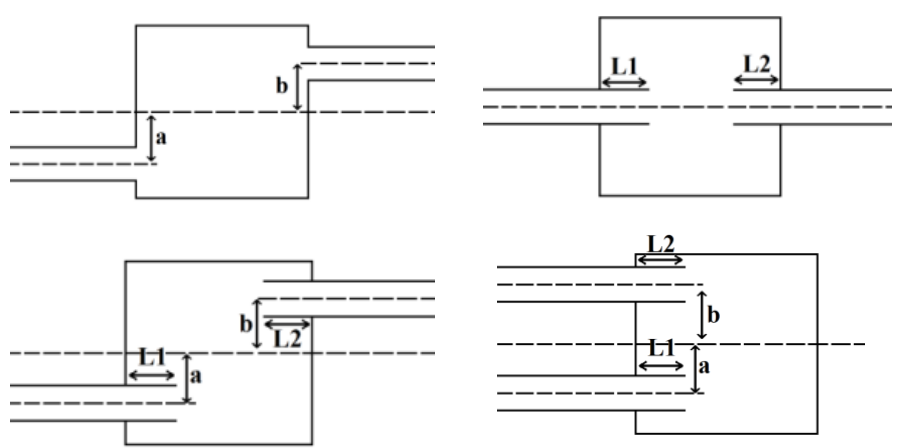

Figure 4. Diagrams of several layouts of tubes and volume

The transient nature of ICE is simulated via a 'shock tube' study. Indeed, the system is closed and sealed, except for an end where a membrane is placed that will be the source of the perturbation (unsteadiness), analogously to the phase of opening / closure of a valve for example.

The main advantages are to monitor and to treat the operation of a single wave generated, to have initial conditions that can be known easily during real tests, easily modify these initial conditions, and use them during simulations.

The models tend to reproduce the real cases performed on a test bench shock tube. Also, all the properties of the fluid will be retained (compressibility, viscosity, density ...) and system characteristics such as area changes, friction and heat transfer.

On the other hand, the three equations of the dynamics of gas and the ideal gas equation will be solved with the use of a method for solving explicit. On the CFD simulations, k- $\varepsilon$ model is used because it is very frequently employed in the referenced papers for its robustness of calculation and its degree of precision with respect to its timeliness of execution. 


\section{EXPERIMENTAL SETUP}

In order to develop the model of the air box and exhaust muffler, the study is performed on a simple configuration. This is selected so as to have the possibility to compare directly the experimental and numerical results. In this way, a shock tube bench [10] is used to produce a realistic pressure wave and can then reproduce as closely as possible the conditions of the simplified model. All tests are performed with an initial temperature equal to the atmosphere. Validation is done by direct comparison of pressure recordings.

\subsection{Shock tube facility}

To determine the influence of different geometries on the pressure pulses, a study is conducted on a bench shock tube $[11,12]$. The advantage of this experimental test bench is to provide an opportunity to test different pressure ratios and to test direct and inverse flow.

Different systems studied constitute directly the shock tube as shown in the figure 5. In this section, all data is provided with this kind of test. The pipeline system is rigidly closed at one end and open at the other end, where a membrane is installed temporarily. Table 1 shows the geometric characteristics of the system and the position of the pressure sensors.

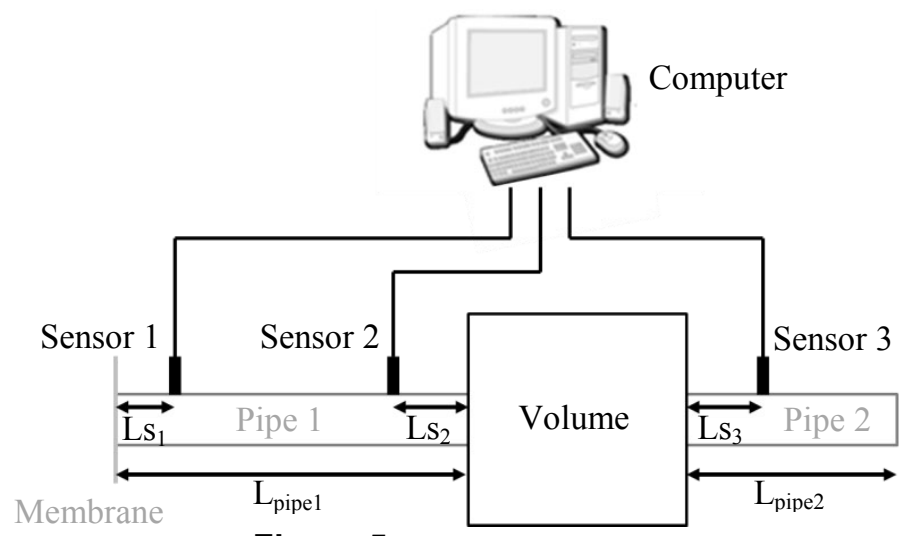

Figure 5. Shock tube bench

Table 1. Main characteristics of pipes system

\begin{tabular}{lc|c}
\hline \multicolumn{2}{c|}{ Characteristic / Unit } & Value \\
\hline $\mathrm{D}_{\text {pipe1 }}$ & $\mathrm{mm}$ & 27 \\
$\mathrm{~L}_{\text {pipe1 }}$ & $\mathrm{mm}$ & 1000 \\
$\mathrm{D}_{\text {volume }}$ & $\mathrm{mm}$ & 95 \\
$\mathrm{~L}_{\text {volume }}$ & $\mathrm{mm}$ & 80 \\
$\mathrm{D}_{\text {pipe2 }}$ & $\mathrm{mm}$ & 27 \\
$\mathrm{~L}_{\text {pipe2 }}$ & $\mathrm{mm}$ \\
$\mathrm{Ls}_{1}$ & $\mathrm{~mm}$ & 500 \\
$\mathrm{Ls}_{2}$ & $\mathrm{~mm}$ & 300 \\
$\mathrm{Ls}_{3}$ & $\mathrm{~mm}$ & 150 \\
\hline
\end{tabular}

After making the desired pressure into the tube, the membrane is pierced $(t=0)$. Flow penetrating from the outside reveals a shock wave that propagates through the duct. The pressure signals are recorded at each end of the volume, but also near the end where the membrane is fixed.

Instantaneous pressure measurements are performed to study the dynamics of the flow. Pressures to the wall of the tube are measured using piezo-resistive sensors. The output of each pressure sensor is pre-amplified and filtered; the sampling rate is $100 \mathrm{kHz}$. The results are post processed with LabVIEW (necessary for using the results).

\subsection{Software}

In addition to bench testing the shock tube, CFD software is used: FIRE [13] developed by AVL. Have recourse to a 3D simulation code will have two purposes, the first is to obtain a three-dimensional visual result of what takes place within the different geometries tested. The second point is that once proved that the CFD code and the real tests on different test cases coincide, FIRE will be used as a digital test bench. In fact, it will no longer be necessary to build and test different geometries on a bench, reducing costs, problems with tests (leaks, measures ...). In addition it will be possible later to test the system at higher pressures (/ depression) and at temperatures other than the atmospheric temperature (to be closer to the maximum of real cases in the exhaust).

Regarding the one-dimensional simulation, it was decided to use a commercial code GT-Power [14], developed by Gamma Technology.

\subsection{Methodology}

An approach in several successive steps has been implemented.

Firstly, the step I is made in order to facilitate the establishment and the good configuration of the calculation codes: a purely analytical case was established. It is considered a tube of two meters and fifty millimetres in diameter, closed at one end rigidly and a membrane is simulated at the other end. The compressible flow is considered, but unsteady inviscid. The goal is to verify the assumptions made on the models and that the Navier-Stokes equations are solved correctly.

The next step (step II) is very similar; the analytic calculation is replaced by actual tests of simple shock tube (single tube). This time, the diameter is equal to 27 millimetres, the length is equal to 1 meter, the viscosity and the heat transfer are taken into account. This step aims to check if the boundary layers are correctly took into account.

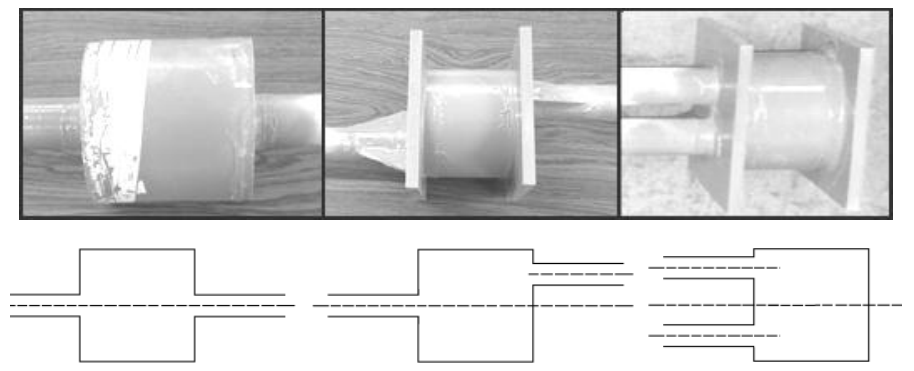

Figure 6. Diagrams of the three representatives geometries 
With the third step, is set up tests for volumes and tubes. It is about testing three representative geometries, as summarized by the diagrams in figure 6 . The goal is to verify that the mesh is properly constructed in each of the configurations that you want to achieve.

The fourth step is the longest. Indeed, it is claimed using the CFD program as a digital test bench. Previous stages once validated solve the problem of the accuracy of the threedimensional simulation. However, such simulations have a counterpart which is a relatively long computation time and is particularly intensive computing resources. This step includes the tests for geometries with tubes penetrating into the volume.

It will be noted that the step I (analytic case) was performed a test in depression and pressure (Ptube $=0.8$ bar and Ptube $=1.5$ bar respectively). All other steps were performed at $0.8 \mathrm{bar}, 0.7 \mathrm{bar}$ and 0.6 bar of pressure in the system to multiply the numbers of cases and observe some acoustic phenomena.

Tables 2 and 3 in appendix summarize the conditions and assumptions used during the GT-Power and FIRE simulations.

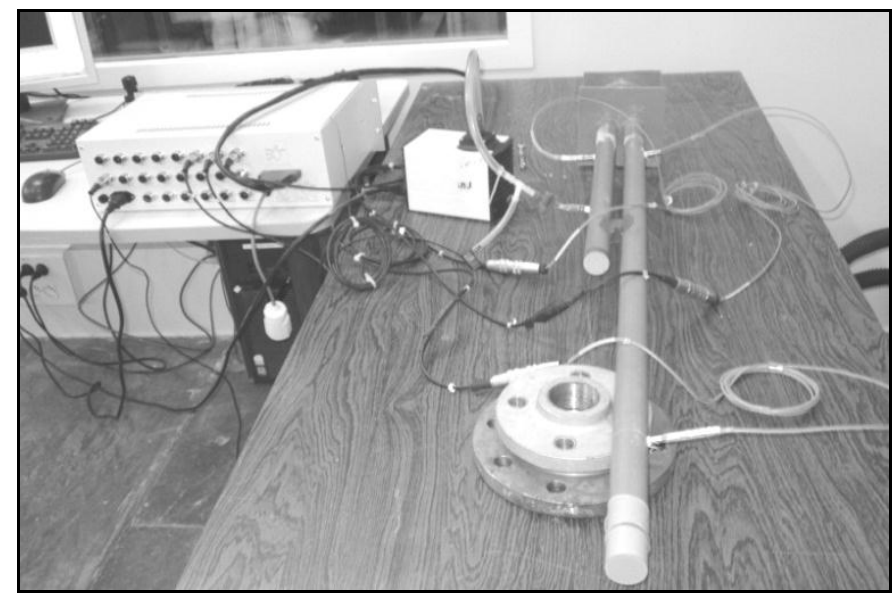

Figure 7. Example of a shock tube bench assembly

\section{MODEL ASSESSMENT}

As discussed in the introduction, in this section the results of different measurements and simulations are presented. The results of each paragraph correspond to those obtained for each step of the methodology in analytical testing, shock tube bench tests and simulations.

\subsection{Shock tube: analytical cases}

No test bench has been performed during this phase. It is mainly used in the correct use of different models and the establishment of equations.

In this way it is possible to obtain the curves above. It will be noted that in both cases, a shock wave and for an expansion wave (figure 8), the results of the two software are quite similar. The final values of simulations coincide with those of the analytical calculation.

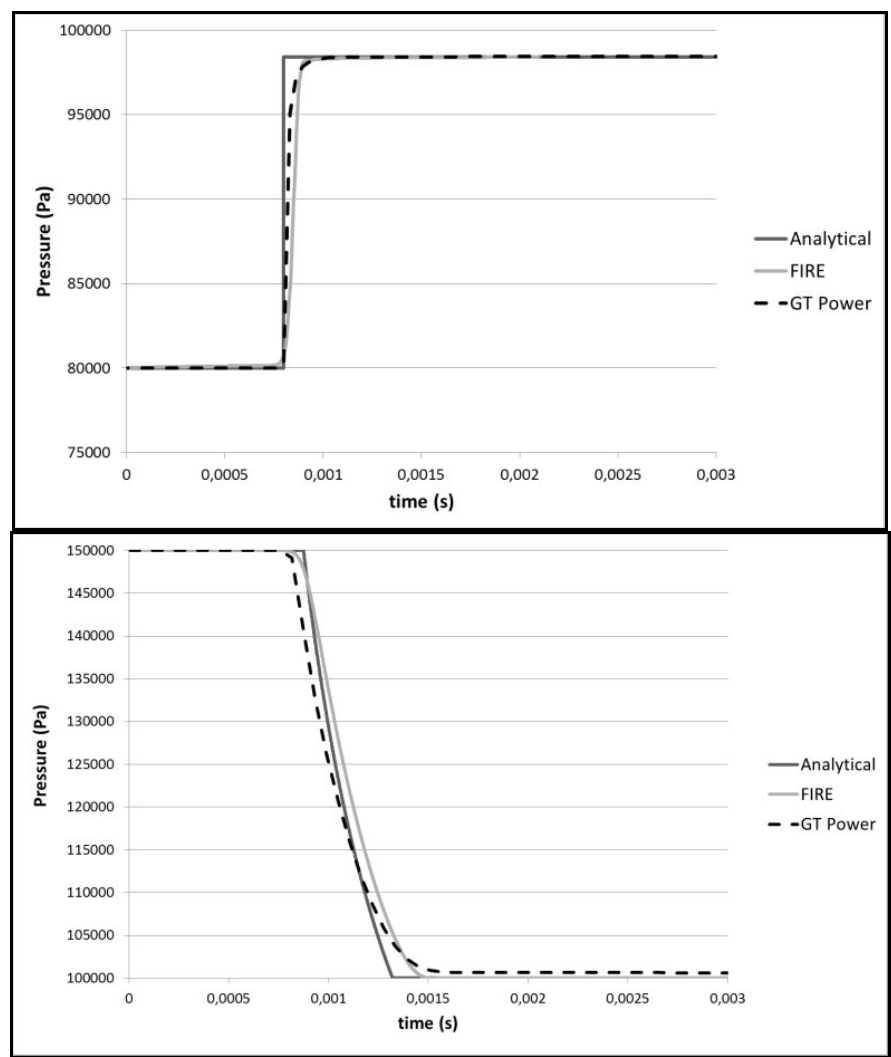

Figure 8. Analytical cases: Pressure wave and Expansion wave

\subsection{Shock tube: real cases}

Several series of tests on shock tubes have been carried out with the aim to obtain experimental results and the least disturbed as possible and close to three initial values of pressure, namely: 0.8 bar, 0.7 bar and 0.6 bar.

$1 \mathrm{D}$ and $3 \mathrm{D}$ simulations were performed based on the same geometrical characteristics as above. It is presented below one of the three cases cited. The one with the initial pressure in the tube that is equal to 0.793 bar. Viscosity and thermal losses are taken into account. In this way, parts of the equations for these two features are enabled in both simulations (with FIRE and GT Power). In the case of the 3D model, three mesh boundary layers are also defined on the walls.

As in analytical calculations, both software give results in accordance with the real tests bench.

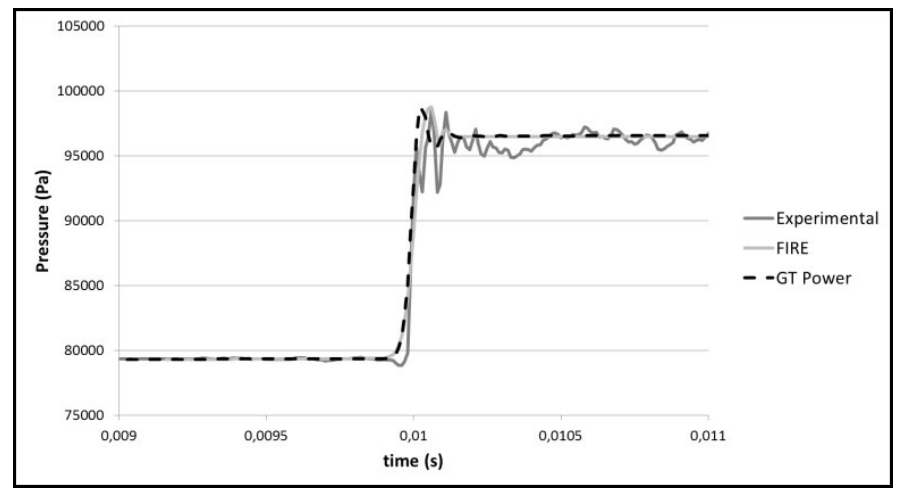

Figure 9. Pressure wave - real case 


\subsection{Shock tube: with viscosity and tubes/volume geometries}

Cases concerning simple tubes were checked. It has therefore been decided to make the system more complex, with 'tube / volume / tube' geometries. In this section, three configurations are choosing as reference case (Figure 6).

The elaboration of geometries involving elements (tubes, volumes, ...) connected to each other with a particular spatial arrangement (as shown in Figures 3-4) may not be an easy thing. 1D allows constructions where the elements are placed end to end, and it can be relatively difficult to make geometries such as in Figures 4, where in two cases the ducts are non-coaxial and penetrate into the volume.

Thus, in order to obtain geometries more accurately described, it was decided to detail the internal geometry of the volume in 1D simulation, breaking it down into different subvolumes so that the ducts are flush and centred with respect to the element that is nearby (Figures 10,11,12).

The shock tube tests performed in the laboratory show small differences with these three cases (figure 13). Nevertheless, there is no really significant change of pressure levels in these test conditions.

Note: $\quad \varnothing 3=95 \mathrm{~mm}$ and $L 3=80 \mathrm{~mm}$

- The volumes V1,V2 and V3 are deducted from divisions as indicated in the diagrams, and then inserted in GT-Power as equivalent volumes.
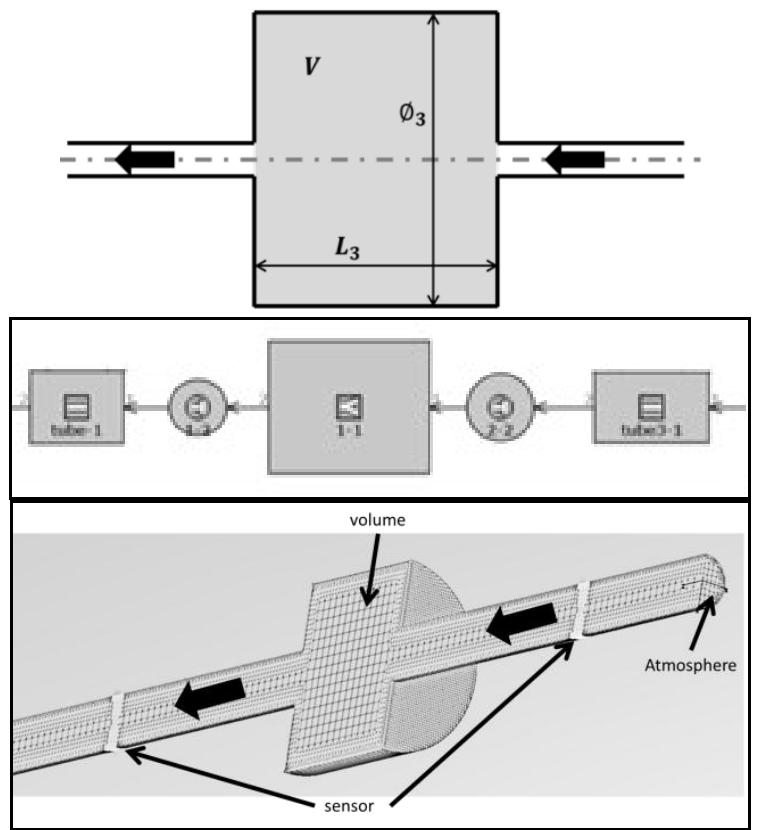

Figure 10. Case I, coaxial tubes and volume: (diagram - GT Power model - FIRE model)

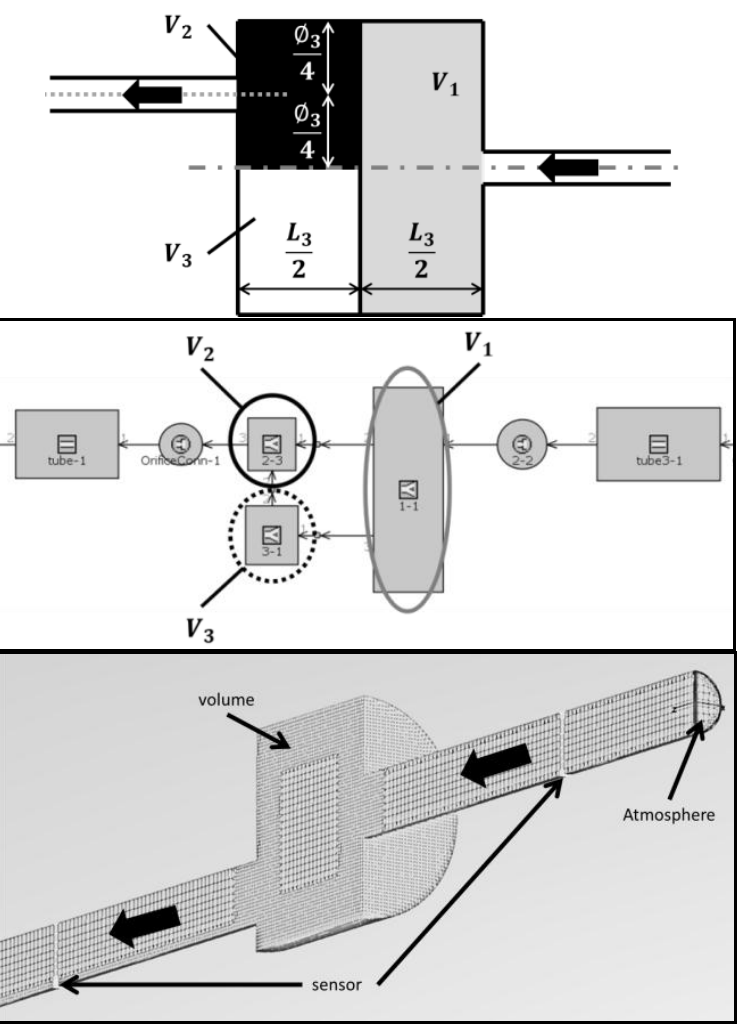

Figure 11. Case II, non-coaxial system: (diagram - GT Power model - FIRE model)

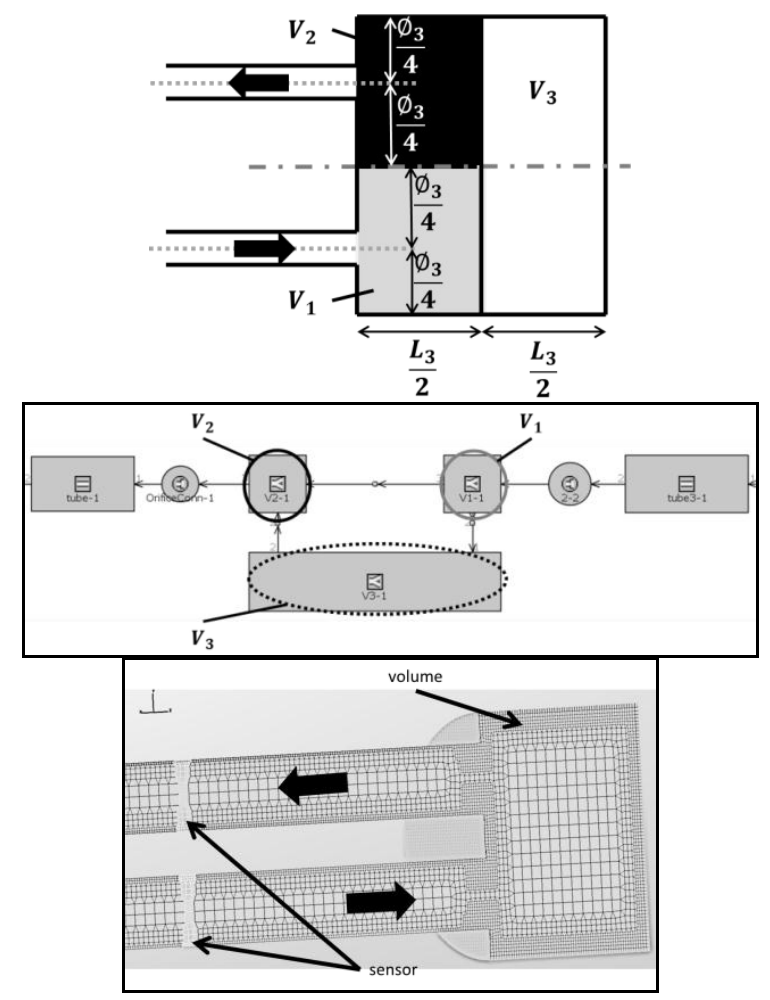

Figure 12. Case III, tubes on the same side: (diagram - GT Power model - FIRE model) 


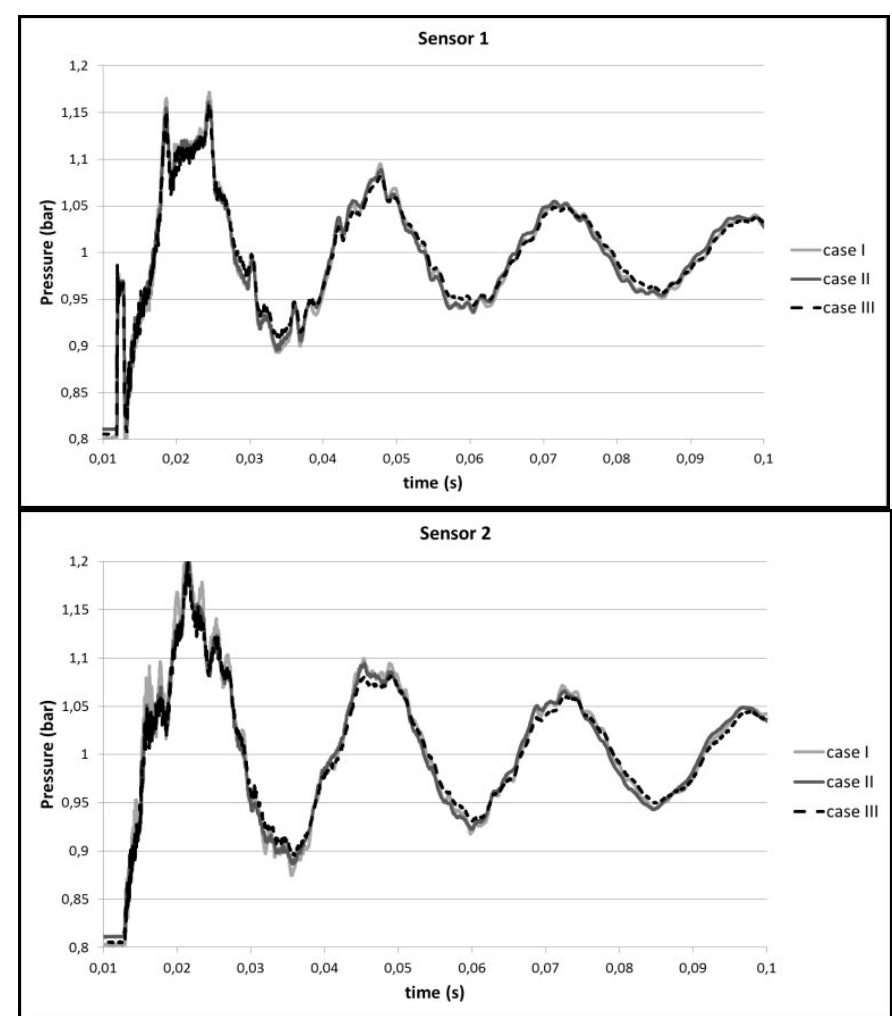

Figure 13. Comparisons of pressure levels between the three cases

This is also an opportunity to check if the 1D models are able to simulate correctly the tests (figures 14, 15, 16):

- Direct comparisons between one-dimensional simulations indicate that the different configurations tested imply little modified results from one case to another. But the proportions remain low (figures 14, 15, 16).

- The following figures show that 3D simulations reproduce with exactness the real tests, and the onedimensional simulations with a wider time scale, provide also realistic results.

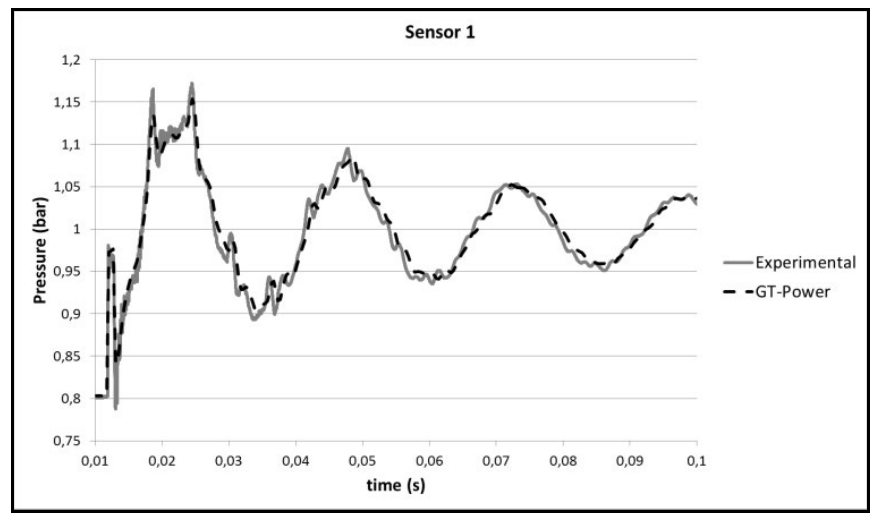

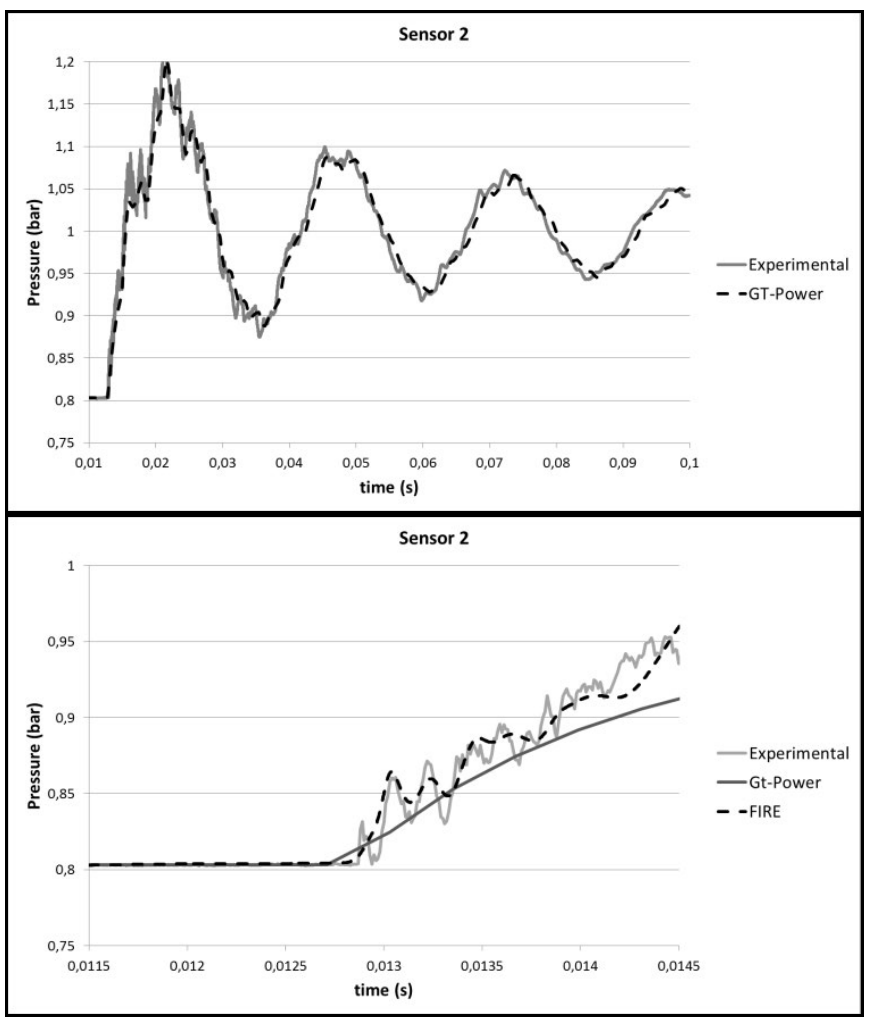

Figure 14. Case I, results for 0,8 bar

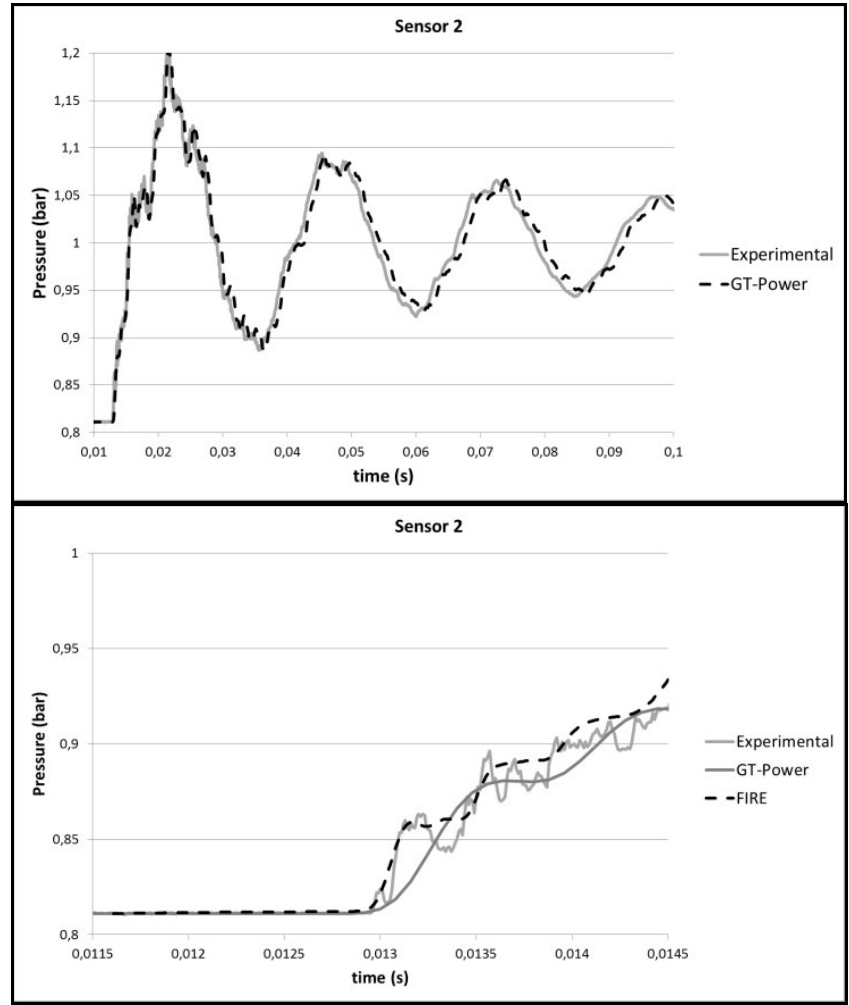

Figure 15. Case II, results for 0,8 bar 


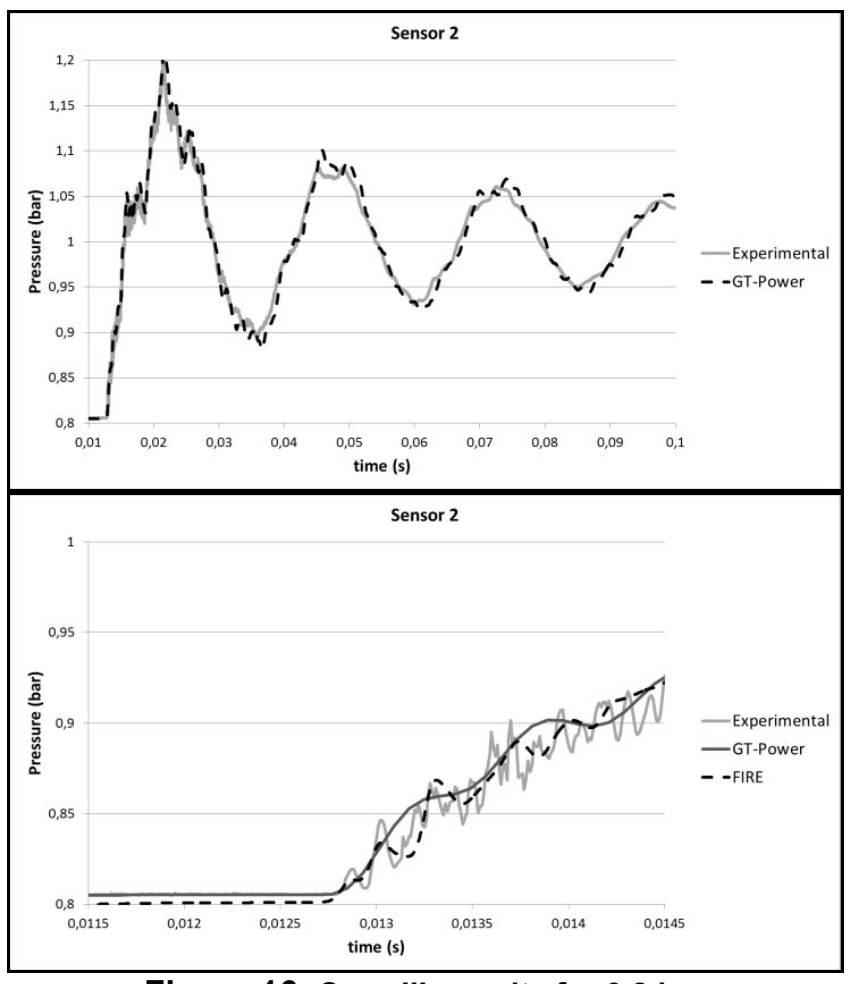

Figure 16. Case III, results for 0,8 bar

\subsection{Shock tube: digital test bench studies}

In this part, the general configuration it is the same as the previous cases, only the length L1 change: L1 is equal to $250 \mathrm{~mm}$ and not one metre as before.

Previously, one has seen that 3D simulation accurately reproduced the pressure variations, including for the small time scales. To these configurations, it results that geometric system modifications involve changes in the results as shown in figures 18. When the tubes are facing, it seems to have a behaviour (and pressure response) different from those where the tubes do not face, especially on the results in the sensor 2 . These differences can be explained by the fact that in the case of tubes are facing on to each other; the pressure wave is transmitted more directly from tube 1 to tube 2 . So the dispersion effect of the pressure is smaller. Cases 1 and 2 have more pressure in the tube 2 than cases 3 and 4

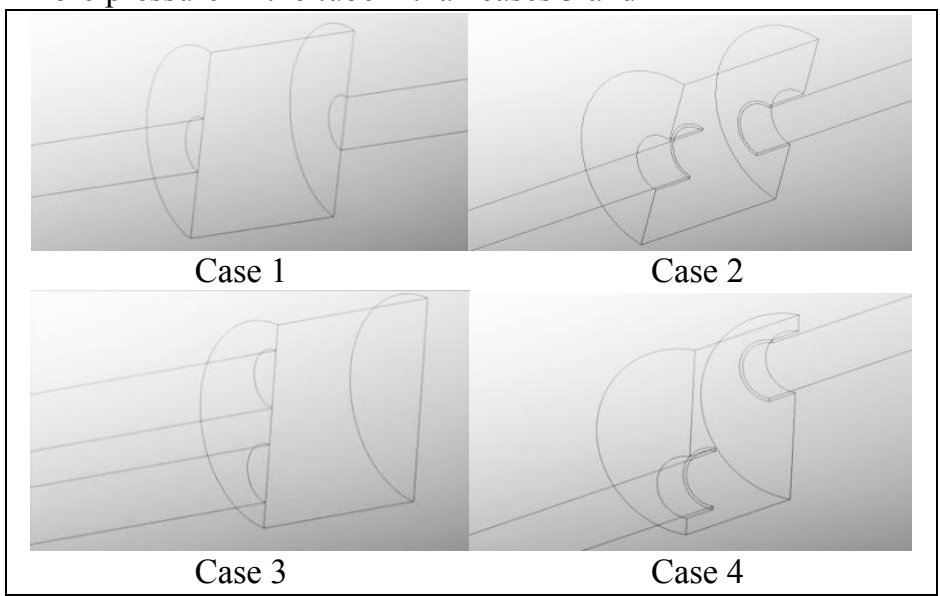

Figure 17. Diagrams of the cases

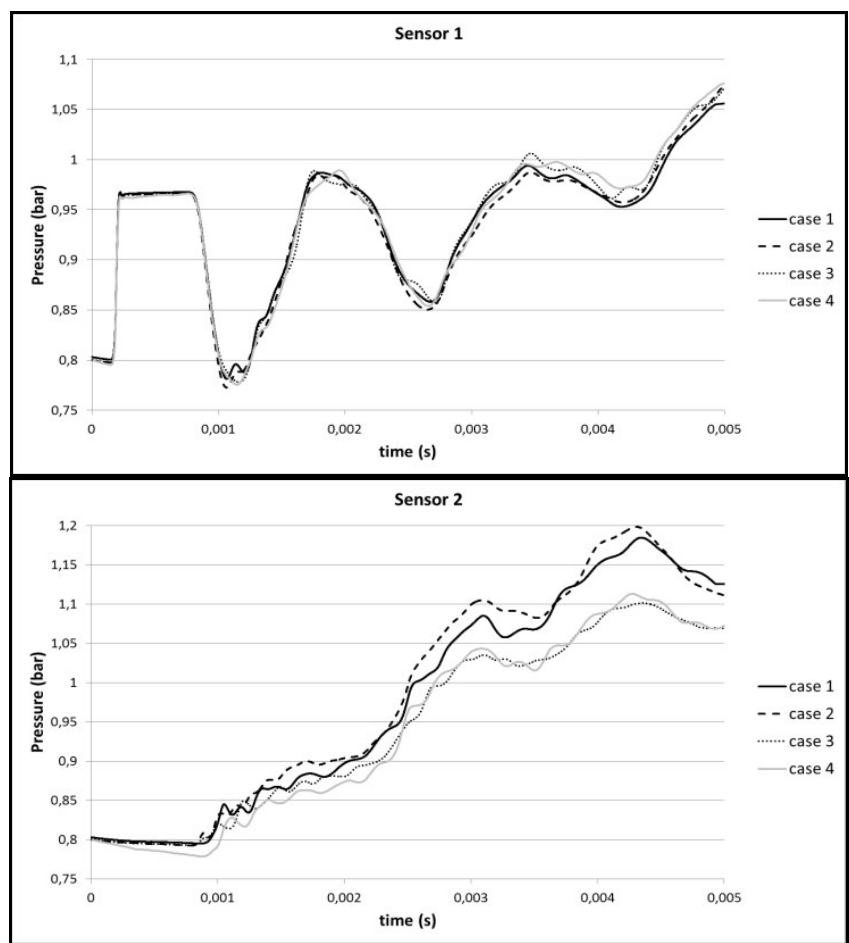

Figure 18. Cases 1-4: results for 0,8 bar ; 3D simulation

The idea is to check if thanks to changes in the construction of the 1D simulation model, it is possible to observe the same pressure levels modifications.

First of all, by comparing directly the different cases to each other, it is possible to note that 'simple' modifications in the construction / structure of a 1D simulation model can affect the results. The differences of pressure levels are relatively small but sufficient to be identified.

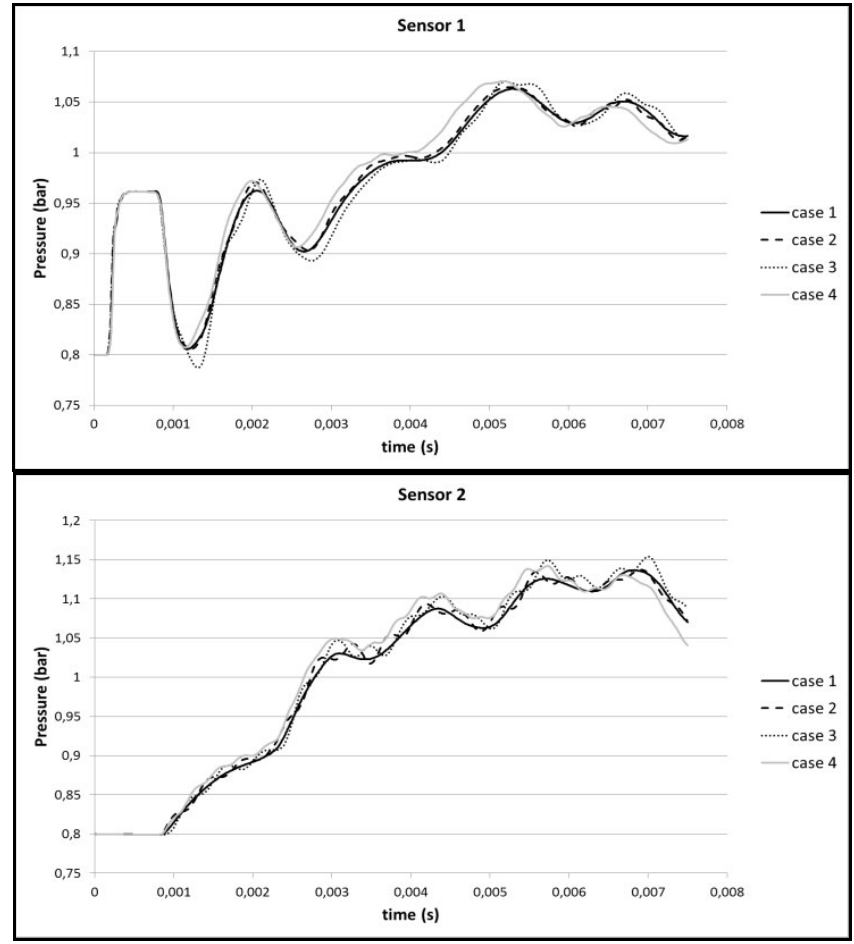

Figure 19. Cases 1-4: results for 0,8 bar ; 1D simulation 
Then, it was proposed to compare the 3D results with those of 1D simulations (direct comparison of the pressure levels). From these graphs, several points emerge:

- In general, on all the cases, pressure oscillations seem to be respected and match between the simulations made with the two softwares. Although after $\mathrm{t}=5 \mathrm{~ms}$, a slight phase difference seems to appear (for example...).

In all cases, it appear that on the time range studied $(\mathrm{t}=[0 ; 8] \mathrm{ms})$, the 1D simulations underestimates the pressure variations.

- Concerning the statement of the sensor 1 (placed between the membrane and the volume, 'upstream' volume), deviations from 2 to $5 \%$ of certain values were observed.

- For downstream of the volume, sensor 2 records provide results with different behaviour of those observed with the sensor 1. Indeed, when the geometries are composed of coaxial elements (cases 1 and 2), the 1D simulation underestimates the acoustic phenomena, pulsations are less pronounced and the difference can exceed 5\%, and reach $10 \%$, as it is possible to see in case $2(\mathrm{t}=4.2 \mathrm{~ms} \rightarrow \zeta=10.1 \%)$.

Will be noted that for cases 3 and 4 , where tubes and volumes are not coaxial, 3D and 1D results are identical (respectively to the other results observed earlier).

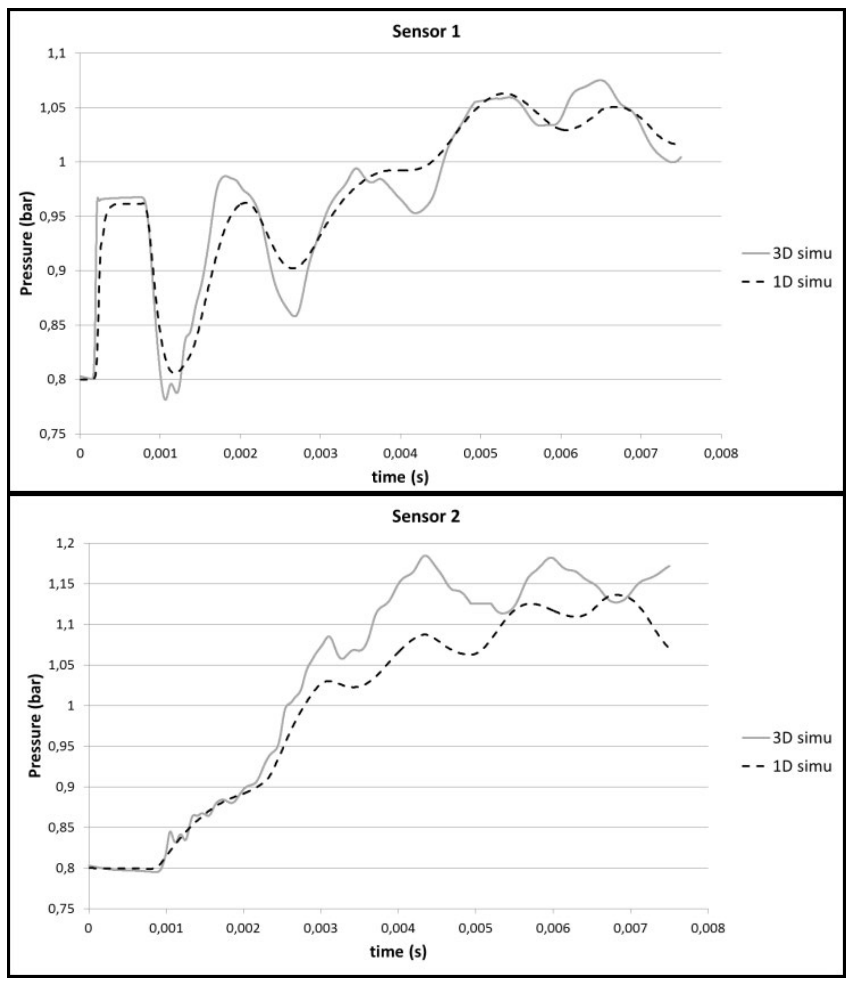

Figure 20. Cases 1

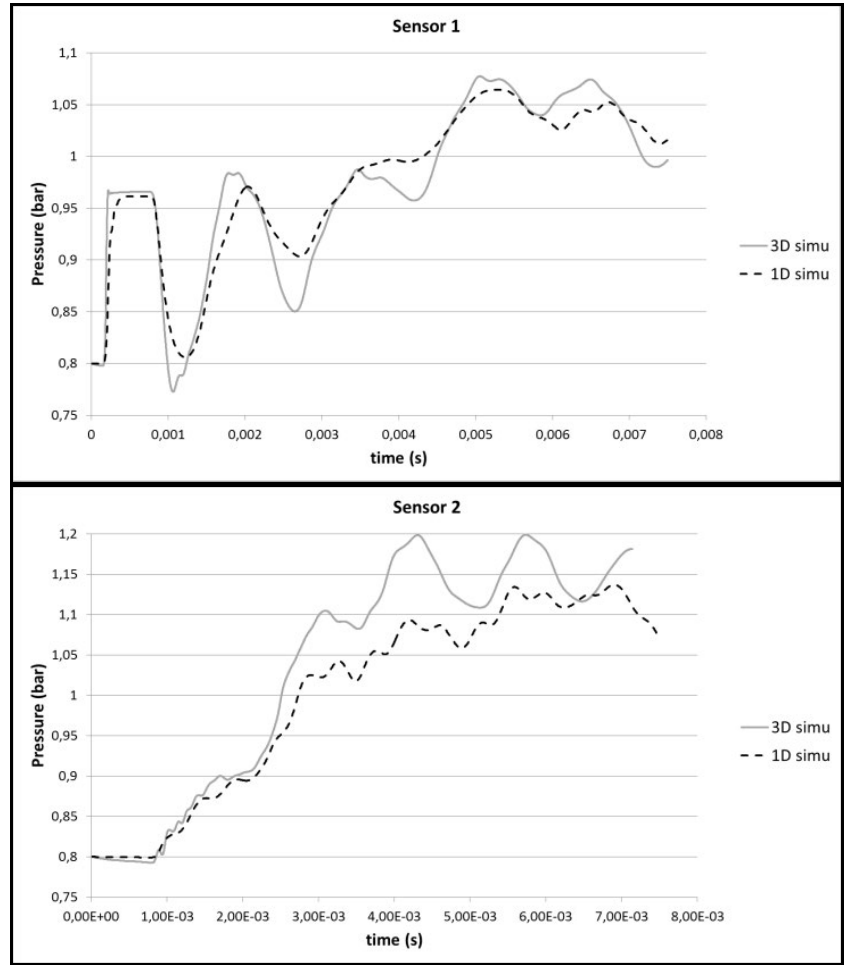

Figure 21. Cases 2

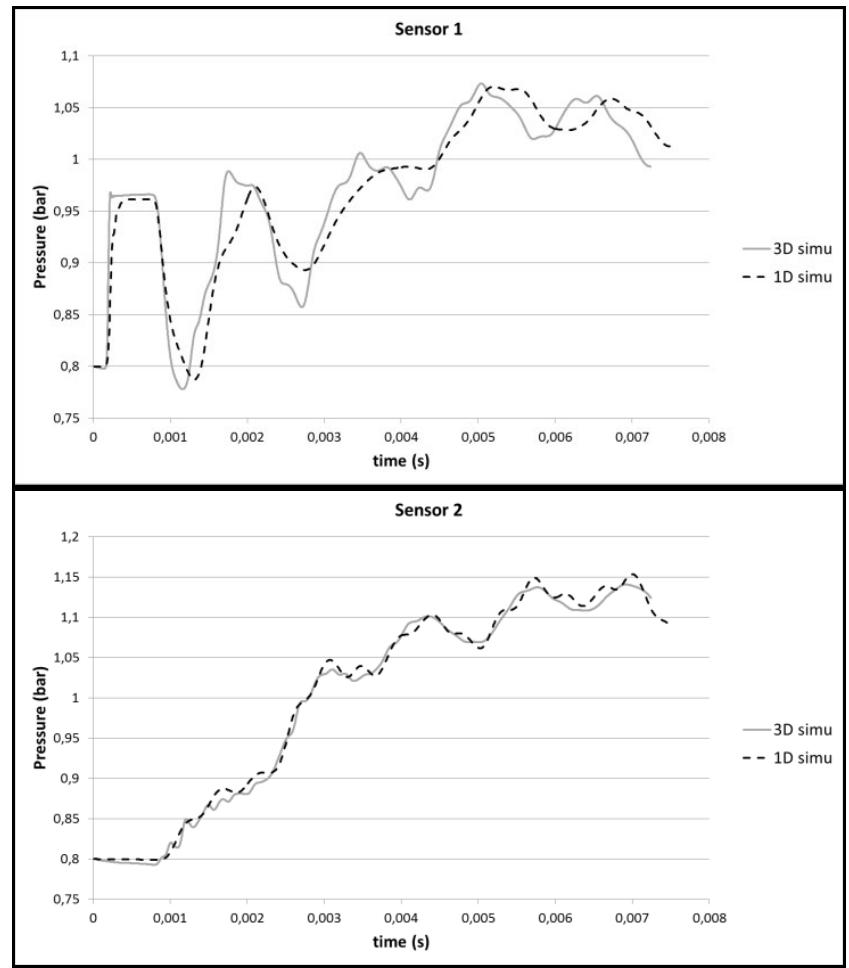

Figure 22. Cases 3 


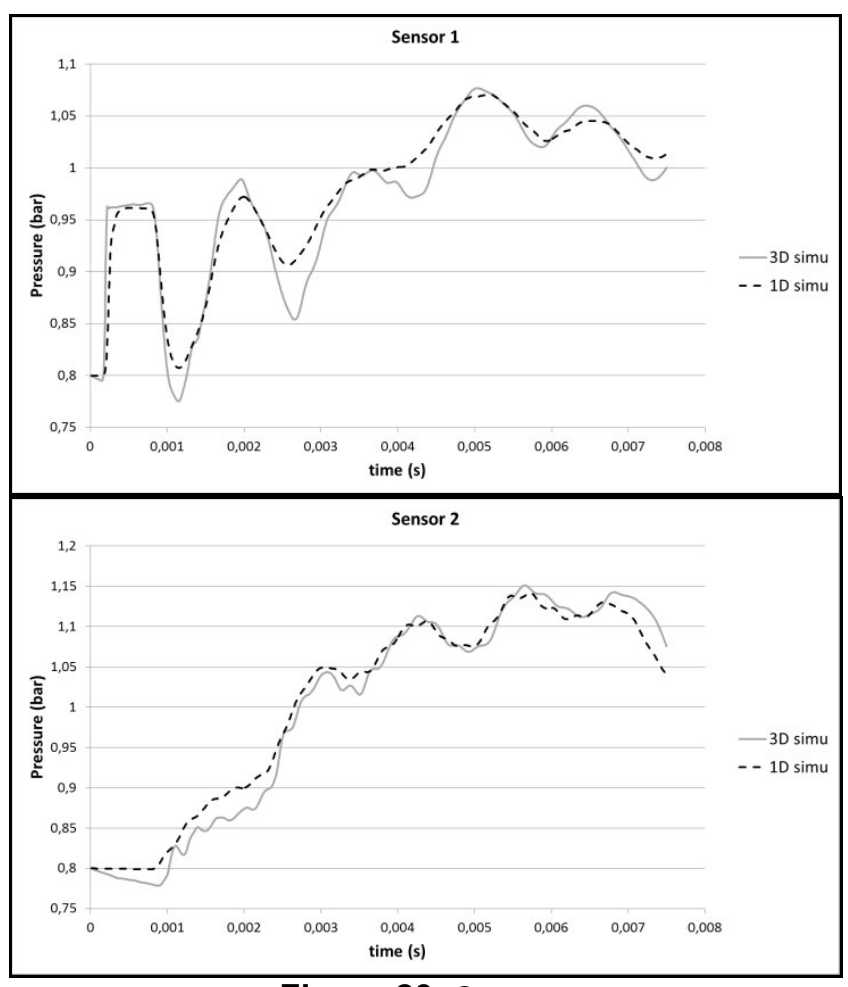

Figure 23. Cases 4

\section{CONCLUSION}

The unsteady flows have an impact on the filling and emptying of the cylinder; is a well-known thing, and it is used on engines. Air boxes and mufflers have direct effect on pressure levels. Therefore, it was proposed to see how $3 \mathrm{D}$ and 1D simulations treat the case of a pressure wave through these elements.

Pressure variations, monitoring of pressure variations, simplicity and the fact that the study can be done again easily, are criteria that have guided the choice to a shock tube study.

The first two steps are used to implement the testing resources (shock tube test bench + softwares) and to verify if the hypothesis and models structures on both simulation softwares are correct.

Step 3 is to compare the real tests (shock test bench) with simulations of the two softwares, with three geometries preselected.

3D simulation seems to be more efficient to represent the reality that the $1 \mathrm{D}$ with reduced time scales ([ms], because 3D require a lot of time to compute and large computing resources). Even if, with a lager time scale ([s]), 1D simulations give results quite satisfactory.

The last step consists to analyse configurations made in the step 3, but also two others new, where temperature is changed $\left(\mathrm{T}^{\circ}=600^{\circ} \mathrm{K}\right)$. The $3 \mathrm{D}$ simulation is selected as a reference because it is supposed to represent more accurately the reality that the $1 \mathrm{D}$ simulation. It has been shown that:

- Pressure levels variations are possible with just purely geometric considerations (different tubes assemblies on a volume element), observed on 3D simulations
- 1D simple constructions, based on the arrangement of equivalent volumes and tubes, provide to vary the pressure levels. The cases presented in this paper are relatively simple; they consisted to divide the 'volume' element in sub-volumes. It can be envisaged, later, to perform other decompositions and/or arrangements of elements in order to represent more accurately the reality.

Nevertheless, there simple modifications show that it is possible in 1D to affect the pressure levels, and to take into account elements of '3D'.

- Step 4 showed that the 1D simulation under-estimated the acoustic effects and variations of the pressure in comparison with 3D simulations; although the tendency is generally respected. This seems to stem from the nature of the 1D simulation and the non-taking into account of the geometry in their entirety.

\section{APPENDIX}

Table 2. Conditions on software: GT Power

\begin{tabular}{|c|c|c|}
\hline & $\begin{array}{l}\text { Analytic } \\
\text { (step I) }\end{array}$ & $\begin{array}{c}\text { Real cases } \\
(\text { steps II, III, IV) }\end{array}$ \\
\hline \multicolumn{3}{|l|}{ Orifice description } \\
\hline $\begin{array}{l}\text { Diameter } \\
\text { Forward discharge coeff } \\
\text { Reverse discharge coeff } \\
\text { Hole thickness }\end{array}$ & $\begin{array}{c}50 \mathrm{~mm} \\
1 \\
1 \\
\text { def }\end{array}$ & $\begin{array}{c}27 \mathrm{~mm} \\
1 \\
1 \\
\text { def }\end{array}$ \\
\hline \multicolumn{3}{|l|}{ Atmosphere } \\
\hline $\begin{array}{l}\text { Pressure } \\
\text { Temperature } \\
\text { Composition }\end{array}$ & $\begin{array}{c}1 \text { bar } \\
293^{\circ} \mathrm{K} \\
\text { air }\end{array}$ & $\begin{array}{c}\text { 1bar } \\
293^{\circ} \mathrm{K} \\
\text { Air }\end{array}$ \\
\hline \multicolumn{3}{|l|}{$\underline{\text { Tubes } \& \text { volume }}$} \\
\hline $\begin{array}{l}\text { Diameter pipe } 1 \\
\text { Length pipe } 1 \\
\text { Diameter pipe } 2 \\
\text { Length pipe } 2 \\
\text { Discretization } \\
\text { Surface roughness } \\
\text { Wall temperature }\end{array}$ & $\begin{array}{c}50 \mathrm{~mm} \\
2 \mathrm{~meters} \\
--- \\
--- \\
2 \mathrm{~mm} \\
0 \\
293^{\circ} \mathrm{K}\end{array}$ & $\begin{array}{c}27 \mathrm{~mm} \\
250 \mathrm{~mm} \\
27 \mathrm{~mm} \\
500 \mathrm{~mm} \\
10 \mathrm{~mm} \\
0 \\
293^{\circ} \mathrm{K}\end{array}$ \\
\hline Initial state & $\begin{array}{c}0.8 \text { bar } \\
275^{\circ} \mathrm{K} \\
\text { air }\end{array}$ & $\begin{array}{c}0.8 \text { bar } \\
275^{\circ} \mathrm{K} \\
\text { Air }\end{array}$ \\
\hline \multicolumn{3}{|l|}{$\underline{\text { Run setup }}$} \\
\hline $\begin{array}{l}\text { Time control flag } \\
\text { Max simulation duration } \\
\text { Min simulation duration } \\
\text { Main driver }\end{array}$ & $\begin{array}{l}\text { Continuous } \\
0.05 \mathrm{~s} \\
\text { def } \\
\text { automatic }\end{array}$ & $\begin{array}{l}\text { Continuous } \\
0.0075 \mathrm{~s} \\
\text { def } \\
\text { automatic }\end{array}$ \\
\hline $\begin{array}{l}\text { Solution method } \\
\text { Real gas option }\end{array}$ & $\begin{array}{l}\text { Explicit } \\
\text { off }\end{array}$ & $\begin{array}{c}\text { Explicit } \\
\text { GTI_cylinder }\end{array}$ \\
\hline $\begin{array}{l}\text { Unsteady friction and } \\
\text { heat transfer model }\end{array}$ & off & V70_b4 \\
\hline $\begin{array}{l}\text { Flow loss model } \\
\text { Mixture viscosity } \\
\text { weighting }\end{array}$ & $\begin{array}{c}\text { Automatic } \\
\text { Mass }\end{array}$ & $\begin{array}{c}\text { Automatic } \\
\text { Mass }\end{array}$ \\
\hline
\end{tabular}


Table 3. Conditions on software: FIRE

\begin{tabular}{|c|c|}
\hline & $\begin{array}{c}\text { Real cases } \\
\text { (steps II, III, IV) }\end{array}$ \\
\hline Duration & $7.5 \mathrm{~ms}$ \\
\hline$\Delta$ time & $10^{-6} \mathrm{~s}$ \\
\hline Mesh & $\begin{array}{c}5 \mathrm{~mm} \text { at the centre } \\
0.625 \mathrm{~mm} \text { at the edges }\end{array}$ \\
\hline Boundary layer & $\begin{array}{l}3 \text { boundary layers define on the } \\
\text { thickness of the edge mesh }\end{array}$ \\
\hline $\begin{array}{l}\text { Equation of } \\
\text { turbulence }\end{array}$ & K-epsilon \\
\hline $\begin{array}{l}\text { Equation of } \\
\text { viscous heating }\end{array}$ & Yes \\
\hline \multirow[t]{2}{*}{$\begin{array}{l}\text { Activate } \\
\text { equations }\end{array}$} & $\begin{array}{l}\text { [ Momentum; continuity; energy; pressure work ] } \\
\rightarrow \text { Yes } \\
{[\text { Scalar ] } \rightarrow \text { No }}\end{array}$ \\
\hline & $\begin{array}{c}\text { Total enthalpy } \\
\text { Compressible fluid }\end{array}$ \\
\hline Wall treatment & Hybrid wall treatment \\
\hline $\begin{array}{l}\text { Heat transfer } \\
\text { wall model }\end{array}$ & Standard wall model \\
\hline Fluid properties & Air_turb Prandtl No : 0.9 \\
\hline $\begin{array}{l}\text { Calculation of } \\
\text { boundary values }\end{array}$ & Extrapolate \\
\hline $\begin{array}{l}\text { Calculation of } \\
\text { derivatives }\end{array}$ & Least Sq. fit. \\
\hline Calculation & Simple \\
\hline & $\begin{array}{l}\text { [ Variable limits; cell quality check; cell face } \\
\text { adjustment equation \& geometry; decoupled } \\
\text { domain; realizability constraints ] } \rightarrow \text { No }\end{array}$ \\
\hline $\begin{array}{l}\text { Convergence } \\
\text { criteria }\end{array}$ & $\begin{array}{c}\text { Max number of iteration: } 40 \\
\text { Min number of iteration: } 3\end{array}$ \\
\hline & $\begin{array}{ll}\text { Normalized residuals: } & \text { pressure }=0.0001 \\
& \text { momentum }=0.0001\end{array}$ \\
\hline $\begin{array}{l}\text { Initial } \\
\text { Conditions }\end{array}$ & $\begin{array}{l}\text { Pressure: } 1 \mathrm{bar} \\
\text { Density: } 1.19 \mathrm{~kg} / \mathrm{m}^{3} \\
\text { Temperature: } 293 \mathrm{~K} \\
\text { Turb. Kin. Energy: } 30 \mathrm{~m}^{2} / \mathrm{s}^{2} \\
\text { Turb. length scale: } 0.003 \mathrm{~m} \\
\text { Turb.diss. rate: } 9000 \mathrm{~m}^{2} / \mathrm{s}^{3}\end{array}$ \\
\hline $\begin{array}{l}\text { Initial } \\
\text { conditions in } \\
\text { tubes/volume }\end{array}$ & $\begin{array}{l}\text { Pressure: } 0.8 \text { bar } \\
\qquad>1.5 \mathrm{~b} \text { for the } 2^{\text {nd }} \text { case of the step } \mathrm{I}< \\
\text { Density: } 1.0138 \mathrm{~kg} / \mathrm{m}^{3} \\
>1.5884 \mathrm{~kg} / \mathrm{m}^{3} \text { for the } 2^{\text {nd }} \text { case of the step } \mathrm{I}< \\
>0.4645 \text { for cases at } 600{ }^{\circ} \mathrm{K}< \\
\text { Temperature: } 293 \mathrm{~K} \\
>600{ }^{\circ} \mathrm{K} \text { for cases at step IV }< \\
\text { Turb. Kin. Energy: } 30 \mathrm{~m}^{2} / \mathrm{s}^{2} \\
\text { Turb. length scale: } 0.003 \mathrm{~m} \\
\text { Turb.diss. rate: } 9000 \mathrm{~m}^{2} / \mathrm{s}^{3}\end{array}$ \\
\hline
\end{tabular}

NOMENCLATURE

\begin{tabular}{|c|c|c|}
\hline Variable & Unit & Description \\
\hline $\mathrm{D}$ & $\mathrm{mm}$ & diameter \\
$\varnothing$ & $\mathrm{mm}$ & diameter \\
$\mathrm{L}$ & $\mathrm{mm}$ & length \\
$\mathrm{Ls}$ & $\mathrm{mm}$ & sensor's position \\
$\mathrm{P}$ & $\mathrm{Pa}$ & pressure \\
$\mathrm{t}$ & $\mathrm{s}$ & time \\
\hline
\end{tabular}

\section{REFERENCES}

[1] Benson R.S., 1982, "he thermodynamics and Gas dynamics of internal combustion engine", vol I, ock JH \& Winterbone DE, Clarendon Press, Oxford

[2] Winterbone D.E, Pearson R.S., 2000, "Theory of engine manifold design. Wave action methods for ICE", Professional Engineering Publishing Limited, London and Bury, St Edmunds, UK

[3] Davies P.O.A.L., 1988, "Practical flow duct acoustics", Journal of Sound and Vibration, 124 (1), pp 91-115

[4] Davies P.O.A.L., Holland K.R., 2001, "The observed aeroacoustic behaviour of some flow-excited expansion chambers", Journal of Sound and Vibration, 239 (4), pp 695-708

[5] Demir A, Büyükaksoy A., 2003, "Transmission of sound waves in a cylindrical duct with an acoustically lined muffler", International Journal of Engineering Science, 41, pp 2411-2427

[6] Munjal M.L., 2003, "Analysis and design of pod silencers", Journal of Sound and Vibration, 262, pp 497-507

[7] Gamma Technology. Inc, 2011, "GT-SUITE: Flow Theory Manual", V.7.2

[8] Chalet D, Chessé P, Hétet JF, 2008, "Boundary conditions modelling of one-dimensional gas flows in an internal combustion engine”, Int.J.Engine Res., 9 , pp 297-282

[9] Chalet D, Chessé P, Hétet JF, Tauzia X, 2009, "Inflow boundary condition for one-dimensional gas dynamics simulation code of internal combustion engine manifolds", Proceedings of the Institution of Mechanical Engineers, Part D: Journal of Automobile Engineering, 223 (7) , pp 953-965

[10] Chalet D, 2003, "Etude et modélisation des ondes de pression dans les géométries complexes. Application à la simulation du fonctionnement d'un moteur à combustion interne", hèse de doctorat, Ecole centrale de Nantes

[11] Chalet D, Mahé A, Hétet JF, Migaud J, 2011, “A new modeling approach of pressure waves at the inlet of internal combustion engines", Journal of Thermal Science, 20 (2) , pp 181-188

[12] Chalet D, Galindo J, Climent H, 2006, "One dimensional modeling of catalyst for Internal Combustion Engine simulation", Spring Technical Conference of the ASME Internal Combustion Engine Division, ICES2006-1400, Aachen, Allemagne

[13] AVL, 2011, "FIRE Workflow Manager: Users Guide", Graz, Austria

[14] Gamma Technology. Inc, 2011, “GT-SUITE: Acoustics Application Manual", V.7.2 